\title{
Development of Infrastructue for Residential Load to Reduce Peak Demand and Cost of Energy in Smart Grid
}

\author{
Hemant I. Joshi ${ }^{1}$, Hemish R. Choksi ${ }^{2}$ \\ Lecturer, Electrical Engineering, Electrical Engineering Department, Government Polytechnic, Ahmedabad, India ${ }^{1}$ \\ Lecturer, Electrical Engineering, Electrical Engineering Department, Government Polytechnic, Himmatnagar, India ${ }^{2}$
}

\begin{abstract}
The renewable energy sources like solar and wind power will be economical in future due to upward pressure in fossil fuel prices, progress in renewable technologies as well as economy scale resulting from large scale production of renewable energy sources. As the usage of renewable energy sources will increase, decentralized supply and demand side management will be used instead of conventional centralized supply side management in future smart grids. Smart meters offer solution to this by allowing more sophisticated measurement of consumption and the implementation of real time pricing. Using power scheduling of appliances we not only reduce the peak demand but operate the appliances when price is low. In this paper real time price based demand response management for residential appliances using intelligent metering and billing system using smart meter is described. Next generation meters will use Automated Meter Reading (AMR) and provide more sophisticated services to the customers. Here architecture of smart grid that is capable of automated reading, alert management (for various events like exceeding peak demand, exceeding monthly target bill etc.) and web dash board to view and control the consumption of various appliances is introduced.
\end{abstract}

Keywords: Smart Grid, Real Time Pricing, Smart Meter, Power Scheduling, Automated Meter Reading.

\section{INTRODUCTION}

The Smart Grid is a web like network in which to-way communication is possible between consumers and utility. As the conventional electric grid is not capable to increase overall system reliability and efficiency; the electric grid must be upgraded. Using communication infrastructure and co-operation of traditional power plant with distributed renewable energy sources such as solar, wind etc. we can reduce the consumption of carbon fuel and emission of green house gases. The consumer can minimize their expenses on energy by adjusting their intelligent appliances operation. Smart grid controls intelligent appliances at consumers home or building to save energy, reduces cost and increase reliability, efficiency and transparency [1]

Fig.1 illustrates the architecture for smart grid communication infrastructure. Demand response services can be enable with help of Information and Communication Technology (ICT) that can respond pricing signal and grid condition signal encouraging consumers to use energy efficiency and reduce peak load through smart grid enabled energy management, results in financial savings for both consumers and electric utilities [2]. Encouraging consumers to use energy efficiently and reduce peak load through smart-grid-enabled energy

management results in financial savings for both consumers and electric utilities [3].

The residential and commercial building sector together is responsible for over $50 \%$ of electricity consumption. The current electricity system doesn't include the active collaboration of parties such as homes and buildings. This limits the effectiveness of energy management efforts. In order to achieve next generation energy efficiency and sustainability, novel smart grid ICT architecture enables the Smart Grids is needed [4]. This architecture enables the aggregation of houses as intelligent networked collaborations, instead of seeing them as isolated passive units in the energy grid.

One of the approaches being used to reduce the peak demand and improve the system reliability is demand response (DR), in which the end users modify their electricity consumption patterns in response to price variations or incentives provided by the utility [5]. In this paper architecture for the integration of smart metering technology into the current system for taking the advantage of lower real time prices is discussed. Using smart meters and Energy Management Controller (HEC) the real time cheap prices are conveyed directly to the customer [6].

One of the approaches being used to reduce the peak demand and improve the system reliability is demand response (DR), in which the end users modify their electricity consumption patterns in response to price variations or incentives provided by the utility [5]. In this paper architecture for the integration of smart metering technology into the current system for taking the advantage of lower real time prices is discussed. Using smart meters and Energy Management Controller (HEC) the real time cheap prices are conveyed directly to the customer [6].

Smart Meters allow electricity distribution system operators to monitor the real time electricity usage of customers. 


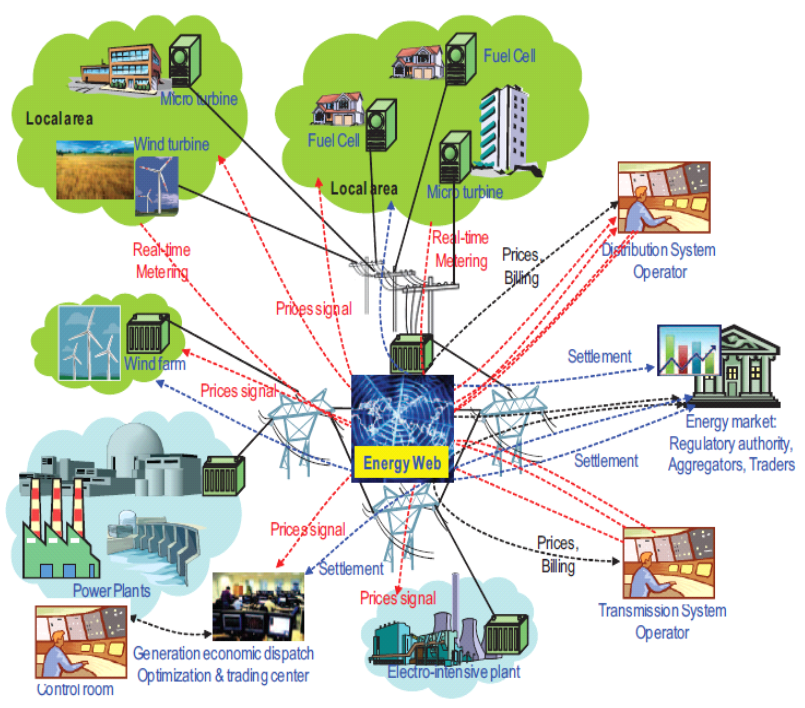

Fig.1. Smart grid Communication Infrastructure

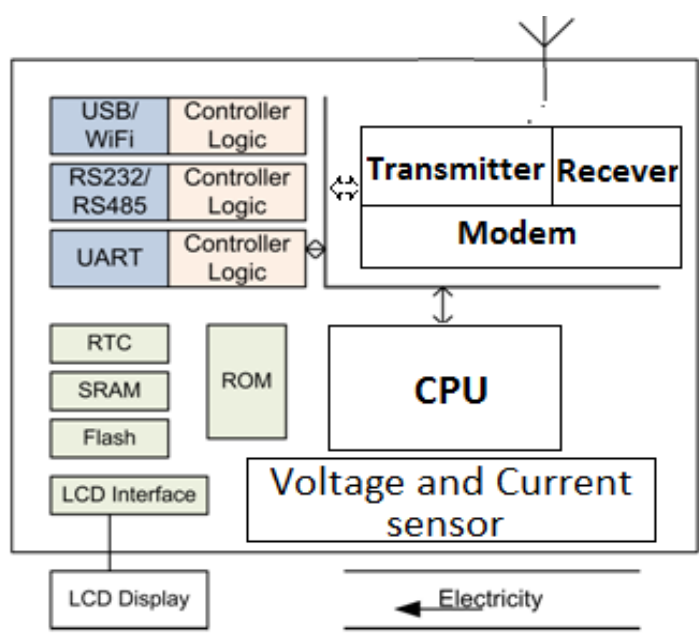

Fig.2 Smart Meter Architecture.

Using Automatic Meter Reading (AMR) consumption For any time span this report can be generated in Excel or information is transmitted to the server of the supplier. At PDF format. Another salient feature of AMR is that utility peak demand times system operators send shedding can enable or disable energy to certain customer if commands to non-essential (or schedulable) appliances.

required.

What AMR can offer is not limited to what has been This paper proposes a real-time price-based DR mentioned above. Generally speaking, having a two way management model for residential appliances, which can communication facility in place definitely it enables many assist residential consumers automatically managing their sophisticated services.

appliances for the optimal energy efficiency and Some manufacturers use PLC (Power Line Carrier), GSM economics. For this purpose a group of 11 houses are (Global System for Mobile) network, telephone lines and selected and smart meter will be installed to all this Short Range Radio Frequency. However these location. Simulation of Home Area Network for one house technologies are not satisfactory. To support more is done here. At present smart meter is installed only at one services, AMR demands investigation into more location. In next phase Home Energy Controller will be sophisticated technologies with higher bandwidth. Third installed to all these houses.

\section{AMR CURRENT TECHNOLOGIES}

The term Automatic Meter Reading (AMR) refers to the technology that helps to collect the meter measurements automatically and send commands to the meters [7]. A key element in an AMR system is communication between networks and utility servers. For data collection the meter can read through a serial port (e.g., RS232), Infra Red or Radio Frequency. Smart meters enjoy high hardware/software capabilities that enable them to run TCP/IP suite and have the ability to run applications on top of TCP. Smart meters are equipped with processing capability ranging from SOC (system on a chip) microcontrollers to 32-bit processors. The operating system, supporting an extensive library of routines and applications, has a task scheduler that rotates between a number of tasks such as communication, measurement and database management. Such architecture is sown in Fig. 2.There are various benefits of AMR. With help of Real Time Pricing signal customers are charged tariffs that vary over short periods of time. It helps customer to control their consumptions and cost of energy they use. The metering data is sent to power company premises and power consumption reports are generated fully automated. and more attention today for their flexibility, easiness and high speed of deployment, cost-effectiveness, scalability, and business needs. Various $3 \mathrm{G}$ wireless technologies have been introduced to the community, some of which had actual implementations. Long Term Evolution (LTE), High Speed Packet Access (HSPA) and IEEE 802.16 (known as Worldwide Interoperability for Microwave Access or WiMAX) comply with International Mobile Telecommunication (IMT-2000).

There are various challenges that must be considered while designing the Smart Meter. The data constitutes small packets transmitted from hundreds of thousands of small devices (meters) very frequently and control data sent down to the meters. Electricity is at the front today, but the challenges apply to all metering data. The AMR application is particularly different in its management of various types of traffic, its tolerance and reaction to failure, its tolerance to delay, and its security needs. One of the important challenges is the security. AMR security must be end-to-end to prevent unauthorized access to the metering equipment or any of the AMR intermediate devices and to prevent tampering with data. Adding security cryptosystems however incurs extra load on the device processing and impacts the energy consumption and bandwidth [7]. Thus, selecting the right cryptographic tool is critical. For example, confidentiality 
of the AMR data is not as critical an issue as is data integrity. Therefore, a strong message authentication protocol is preferred while encryption cryptography can be kept simple.

\section{REAL TIME PRICE BASED DEMAND RESPONSE MANAGEMENT FOR RESIDENTIAL LOAD}

Presently utility companies are using flat rate tariff or time-of use (TOU) rate tariff. Without acknowledging differences

on electricity prices, they do not have incentives to adjust their electricity consumption patterns. Due to the potential benefits the real-time electricity pricing could bring to the demand side, consumers can optimally adjust their energy consumptions by participating into the demand response (DR) program for minimizing the electricity bill [6]. DR is one of the key components in smart grid, which will help power markets set efficient energy prices, mitigate market power, improve economic efficiency, and increase security. Although the real-time pricing incentive may introduce financial risks to end customers as compared to the flat rate or TOU rate, it brings additional benefits to enhance the operational security and economics of power systems. A comparison of TOU and real-time pricing is indicates that high resolution real-time pricing signals will carry on more real-time operation information of power systems, which would bring more benefits to power systems in terms of flattening the system load profile and reducing the peak demand as compared to TOU rates. Thus, passing real-time pricing to a demand aggregator while still using TOU for individual end customers may not provide enough information on the true time-variant electricity supply costs or enough financial incentives to end customers to adjust their energy consumptions and, in turn, will not fully realize the benefits of DR. Smart meters will enable real-time bidirectional communication and control between the demand side and the electricity market, which allow consumers to receive real-time electricity prices.

In order to minimize the total electricity payment, pricebased DR consumers could respond to time varying electricity prices and shift their consumptions to the periods of relatively low electricity prices.

Fig. 3 shows the typical RTP signal sent by utility. During peak time the price of energy is kept higher to reduce the peak demand. Incentive based and price based DR programs can be used. Incentive based DR program offers customers some monetary bonus to reduce the load upon operator's request. Price-based programs allow customers to voluntarily adjust their demand based on electricity prices [7]. In such price-based programs the RTP signal shown Fig. 3 is used.

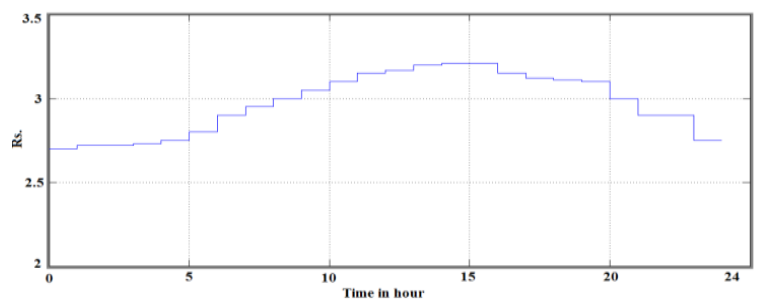

Fig.3. Real Time Pricing signal
For metering purposes, each day is divided into 30-minute or one hour interval. Therefore there are 48 or 24 intervals of each day.

If we take 24 time intervals, these time intervals are incrementally indexed by $x$, where $0 \leq x \leq 24$. For a customer $c$ the flat rate tariff is $P f_{c x}$ (In currency unit per hour). The price fluctuation of $P f_{c x}$ at time index $x$ is denoted by $\mathrm{D}_{c x}$. We assume that the price fluctuation can be reduction or a penalty to the customer (depending on various factors), and its punitive upper bound $\left(\mathrm{B}_{u}\right)$, lower bound $\left(\mathrm{B}_{l}\right)$ and distribution is set by the supplier:

$\mathrm{B}_{l} \leq \mathrm{D}_{c x} \leq \mathrm{B}_{u}$ for all $x$

From (1) we can define the real-time price as

$P r_{c x}=P f_{c x} \pm \mathrm{D}_{c x}$ for all $x$

In countries like India still such price-based programs are not used. DR is an alternative solution to reduce peak loads and adjust the demand in peak times to postpone the investment in new generation capacity. Moreover, in regions with high penetration of renewable energy sources, DR can trigger the change of demand to follow the change of supply [8]. DR architecture centred on an HEC which interconnects the Home Area Network and Advanced Metering Infrastructure (AMI) domains, as seen in Fig. 4. Real time pricing and DR signals are sent to the smart meter via the electric utilities neighbourhood area network (NAN) with the neighbourhood transformer serving as the aggregation point for all the smart meters in that region. The HEC monitors the operation of all the attached smart appliances. It then uses current electricity prices to determine:

- The operation mode of each device

- The load scheduling strategy required to balance occupant comfort and electricity usage.

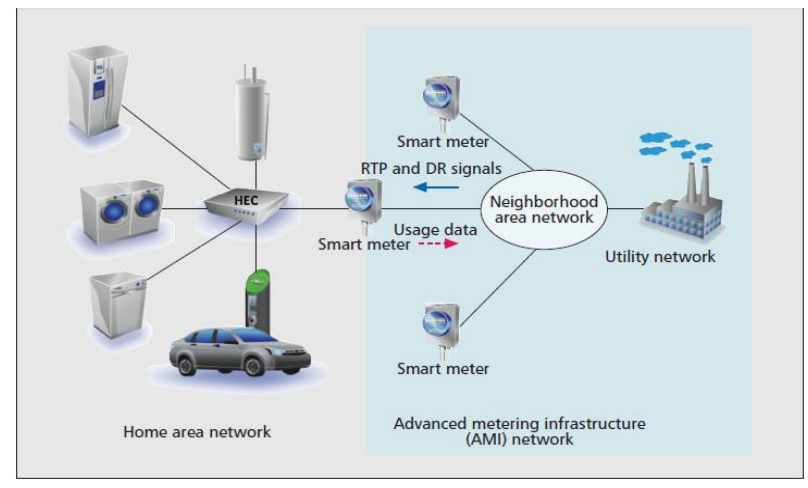

Fig.4. System Model

Plug in electrical vehicle can be designed smarter schedulable appliance as most vehicles can reasonably be expected to be plugged in for 10-15 hours a day (more for vehicles that are regularly plugged in both at home and at work). Smart charging is more than just charging at offpeak times. It involves fine-grained control of the charging of each vehicle to meet both the needs of the vehicle owner (charging the vehicle by a certain time) and the needs of the grid (matching generation and load, providing frequency regulation, and perhaps also avoiding overload in distribution networks from many vehicles being charged at the same time) [9].

DOI 10.17148/IJIREEICE
126 
The smart appliances will have two-way communication with the HAN control centre. Each smart appliance has an IC built in to report the status and to receive the control signal. Recently, some home electronics companies such as General Electric have already started to produce smart appliances with IP based remote control signal receiver [10]. To evaluate the DR impacts on consumer daily life, comfort indices are needed to measure consumer comfort levels. The consumer convenience indices are defined based on the severity, scale, and duration of convenience violations for each controllable appliance [10].

\section{IV.POWER SCHEDUALING MODEL IN HOME AREA NETWORK}

\section{A. Scheme For Reducing Peak Demand and Cost of Energy}

We assume here that real-time prices are used to calculate, $\mathrm{P}_{\text {max }}, \mathrm{t}$, a target power consumption level for the home at time t. For example, this target value can be obtained by incorporating current electricity prices with the customer's budgetary preference (e.g., no more than Rs.x to be spent on electricity bills this month) and their usage pattern (e.g., total cost incurred thus far this month and expected usage for the remainder). Or it could be a power level set by the utility, e.g., as a part of a (Direct Load Control) DLC program.

We here further assume that on the availability of renewable energy in the grid and weather there is peak load on the power station or not, the utility sends Real Time Pricing (RTP) signal to HEC. Our joint media access and appliance scheduling approach gives an access method for the common control channel of the HAN so that appliances can coordinate usage and meet the target $P_{\max }, t$ [11]. Two types of appliances are accommodated. First are "real-time" which are granted immediate access to the active set (i.e., those that must be turned on immediately); the second are "schedulable" which can be turned on at a later time. Results show that for an appropriate $P_{\max }, t$, this scheme leads to a reduced peak demand for the home and reduces the cost also.

The goal of the scheme presented here is to exploit the "schedulability" of smart appliances to bring peak usage at or below the threshold power level. We note, however, that certain usage patterns will not permit total usage below $P_{\max }, t$; in such cases, our scheme will attempt to reduce overall usage close to $P_{\max }, t$ with the understanding that the customer will have to pay more for the higher demand.

Fig. 5 shows the block diagram of Home Area Network considered in our case. Here all the appliances are either smart appliances or receive power through smart plugs that senses the signal sent by HEC. The consumption of each device is shown in each block. Utility may sends the Real Time Pricing signal via Wimax , Power Line Carrier (PLC) or GPRS. Fig. 6 shows the proposed infrastructure that will be used in pilot project.

\section{B. Block Diagram of Home Area Network}

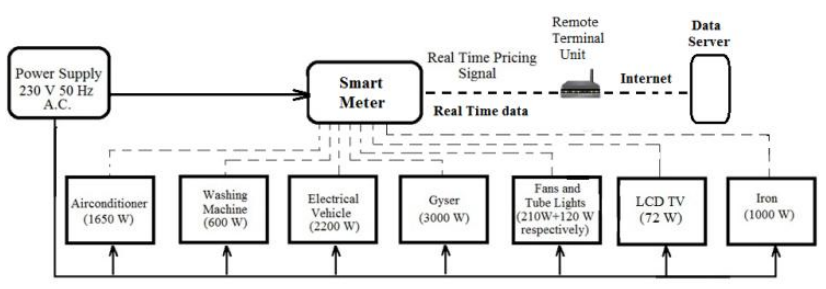

Fig.5. Block diagram of Home Area Network

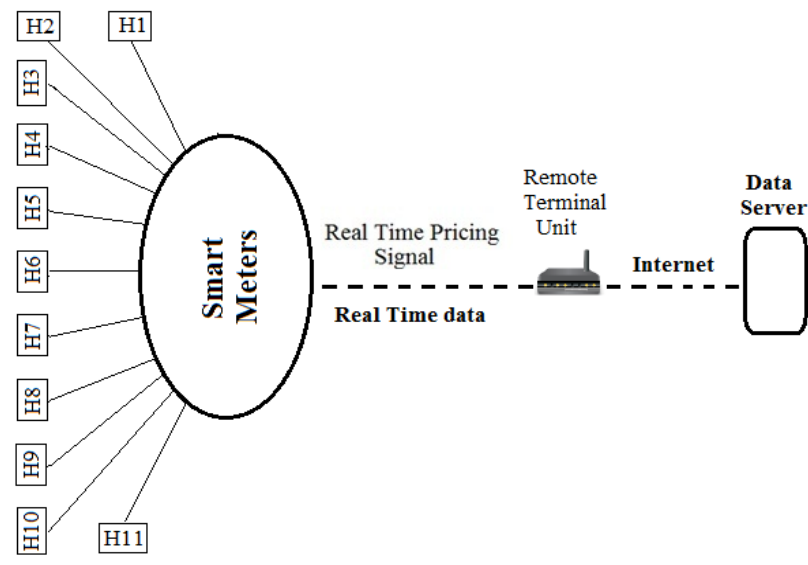

Fig. 6 Infrastructure for the pilot project

The appliances may connect with HEC via Wi-Fi, Zigbee or wired connection. In this case the connection is done (for exchanging signals) with control cables. If utility sends RTP signals regularly, the HEC tries to allow the schedulable appliances during the time of lower energy cost. By this manner the overall cost of energy consumed is minimized. As shown in in Table I appliances operate without RTP signal. Table-II shows the operation of appliances controlled by HEC so the peak demand remains at $3 \mathrm{~kW}$.

TABLE I

Typical use of appliances without HEC

\begin{tabular}{|c|c|c|c|c|}
\hline $\begin{array}{c}\text { Sr. } \\
\text { No. }\end{array}$ & $\begin{array}{c}\text { Appliance } \\
\text { Name }\end{array}$ & No.s & $\begin{array}{c}\text { Consumption } \\
\text { Watt }\end{array}$ & $\begin{array}{c}\text { Duration } \\
\text { hours }\end{array}$ \\
\hline 1 & Split A/C & 1 & 1650 & $\begin{array}{c}13: 00 \text { to } 17: 00 \\
22: 00 \text { to } 7: 00\end{array}$ \\
\hline 2 & $\begin{array}{c}\text { Washing } \\
\text { Machine }\end{array}$ & 1 & 600 & $9: 00$ to $10: 00$ \\
\hline 3 & E.V. & 1 & 2200 & $\begin{array}{c}7: 00 \text { to } 8: 00 \\
21: 00 \text { to } 23: 00\end{array}$ \\
\hline 4 & Gyser & 1 & 3000 & $7: 00$ to $8: 00$ \\
\hline 5 & Fan & 3 & 210 & $\begin{array}{c}9: 00 \text { to } 11: 00 \\
18: 00 \text { to } 22: 00\end{array}$ \\
\hline 6 & Tube-Light & 3 & 120 & $18: 00$ to 22:00 \\
\hline 7 & LCD TV & 1 & 72 & $18: 00$ to 22:00 \\
\hline 8 & Iron & 1 & 1000 & $8: 00$ to 9:00 \\
\hline
\end{tabular}


TABLE II

Typical use of appliances controlled by HEC

\begin{tabular}{|c|c|c|c|c|}
\hline $\begin{array}{c}\text { Sr. } \\
\text { No. }\end{array}$ & $\begin{array}{c}\text { Appliance } \\
\text { Name }\end{array}$ & No.s & $\begin{array}{c}\text { Consumption } \\
\text { Watt }\end{array}$ & $\begin{array}{c}\text { Duration } \\
\text { hours }\end{array}$ \\
\hline 1 & Split A/C & 1 & 1650 & $\begin{array}{c}13: 00 \text { to } 17: 00 \\
22: 00 \text { to } 7: 00\end{array}$ \\
\hline 2 & $\begin{array}{c}\text { Washing } \\
\text { Machine }\end{array}$ & 1 & 600 & $9: 00$ to $10: 00$ \\
\hline 3 & E.V. & 1 & 2200 & $\begin{array}{c}7: 00 \text { to } 8: 00 \\
20: 00 \text { to } 22: 00\end{array}$ \\
\hline 4 & Gyser & 1 & 3000 & $8: 00$ to $9: 00$ \\
\hline 5 & Fan & 3 & 210 & $\begin{array}{c}9: 00 \text { to } 11: 00 \\
18: 00 \text { to } 22: 00\end{array}$ \\
\hline 6 & $\begin{array}{c}\text { Tube- } \\
\text { Light }\end{array}$ & 3 & 120 & $18: 00$ to $22: 00$ \\
\hline 7 & LCD TV & 1 & 72 & $18: 00$ to $22: 00$ \\
\hline 8 & Iron & 1 & 1000 & $10: 00$ to $11: 00$ \\
\hline
\end{tabular}

The time of use of the appliances will be clear with help of wave-forms in the following section.

\section{Simulation Results}

Simulation is done with help of MATLAB R2011a software. Fig. 7 shows the simulink model of HAN.

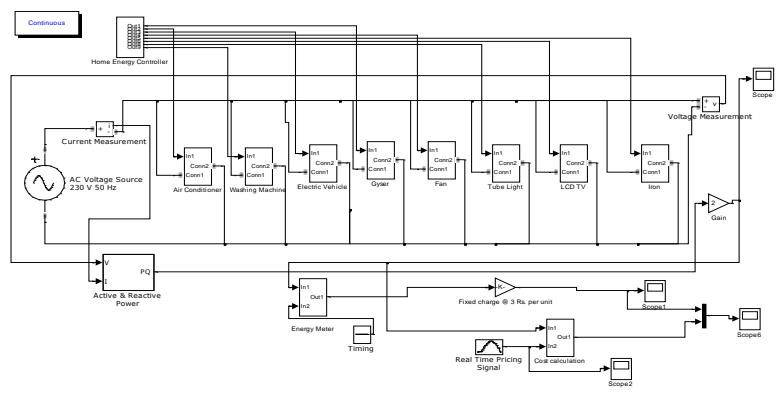

Fig.7 Simulink Model of Home Area Network

Fig.8 shows the load curve for the time of use of appliances as tabulated the data in Table-II. Here the appliances are operated without help of HEC. Peak demand is $3 \mathrm{~kW}$.

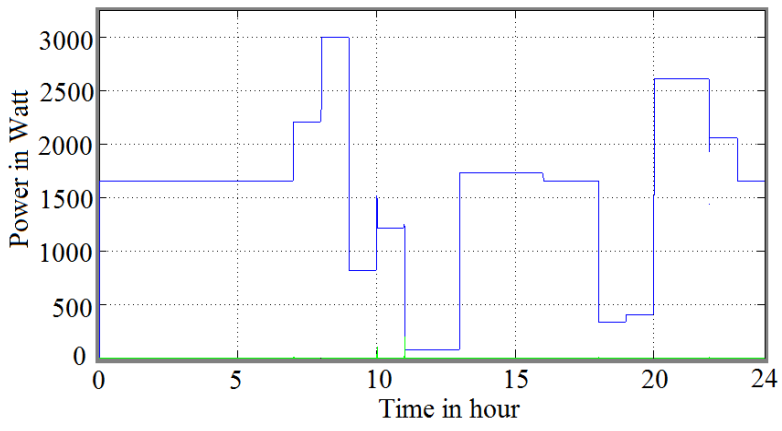

Fig.8. Load curve without power scheduling

Fig. 3 shows the typical RTP signal sent by utility. During peak time the price of energy is kept higher to reduce the peak demand. Incentive based and price based DR programs can be used. Incentive based DR program offers customers some monetary bonus to reduce the load upon operator's request. Price-based programs allow customers to voluntarily adjust their demand based on electricity prices [8]. In such price-based programs the RTP signal shown Fig. 3 is used.

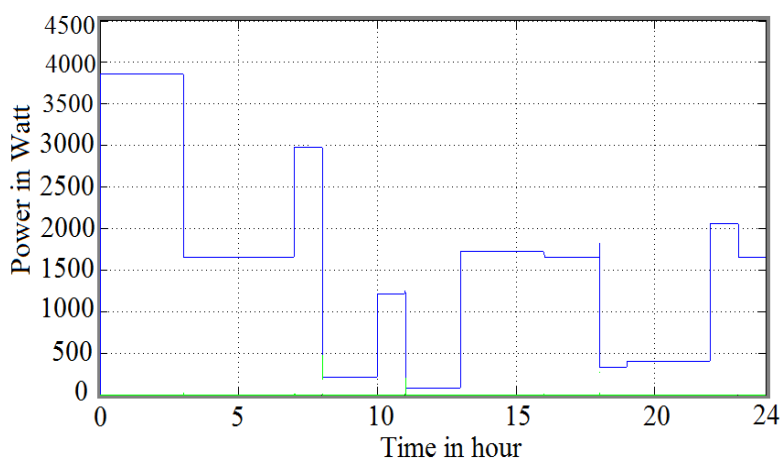

Fig. 9. Load curve with shifting of load of EV and Washing Machine

In countries like India still such price-based programs are not used. Normally constant value per unit is applied during the whole day. So to calculate the cost of energy consumed, both the cases are considered in this simulation. In first case the total cost of energy consumed during the day is calculated using the rate Rs. 3 per unit. In second case the price-based incentive scheme is used to calculate the total cost of energy used. For this RTP signal is generated in the simulink model shown in Fig. 7.

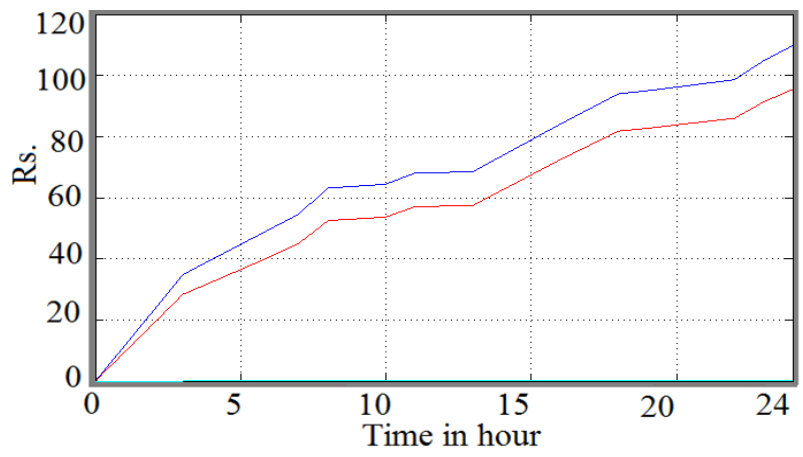

Fig.10. Cumulative cost of energy consumed with shifting of load when energy charge is lower. Upper trace: Cost without power scheduling. Lower trace: cost with power scheduling.

According to RTP signal shown in Fig. 3, the charge of energy is lower during period 00:00 to 06:00. So if we shift the charging of EV during period 00:00 to 03:00 and use of washing machine during the period 22:00 to 23:00, as shown in Fig. 9, the cost of energy reduces. As shown in Fig. 10, the total energy cost of the day remains same without power scheduling (i.e. Rs. 112). With shifting of load of EV and washing machine during lower energy charge period, the total energy cost of the day is Rs. 94. So Rs. 4 (or $4.1 \%$ ) are saved per day by shifting of load during lower energy charge period. However reducing the cost of energy by this manner, the peak load increases to $3850 \mathrm{~W}$ (instead of $3000 \mathrm{~W}$ ).

\section{VI.IMPLEMENTATION OF DEMAND SIDE MANAGEMENT}

The unique function of the proposed metering and billing system for the pilot project is its embedded demand side load management. 


\section{A. Smart Meters}

Smart electricity meters are the basic components in this system. They collect the data and send it to server through GPRS. General packet radio service (GPRS) is a packet oriented mobile data service on the $2 \mathrm{G}$ and $3 \mathrm{G}$ cellular communication system's global system for mobile communications (GSM).

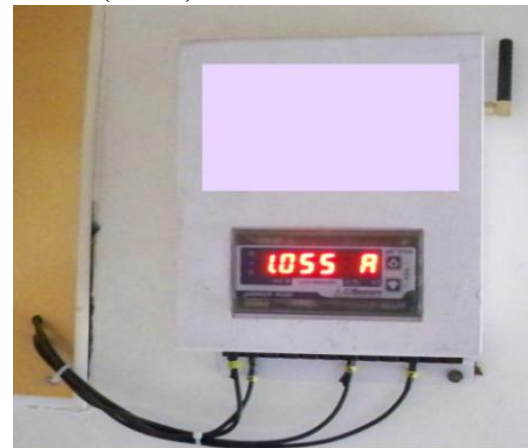

Fig. 11 View of Smart Meter (It displays current)

\section{$B$. Database and management system}

Customer information is stored in both local and central database. Local database centre stores from several nearby buildings. All of the data from the local database can be exchanged between central database and local database.

Information stored in the database include:

Customer data: customer name, address, customer ID, purchase and payment plans, real time energy consumption for each slot and balance etc.

Company data: supplier name, address, company ID and promotion plans etc.

In this project suppliers information is not mentioned because dummy meter is used and the server used is not of utility.

In Fig. 12 web portal used for this project is shown. Various types of parameters like Current, Voltage, $\mathrm{kW}$, $\mathrm{kVA}$, power factor, $\mathrm{kWh}$ for any time duration (e.g. today, last week, this month or between any required dates) can be fetched. The readings of various parameters are updated at every minute.

There would be an option to receive SMS alert/e-mail alert when demand exceeds the contract demand. The Fig. 13 shows the window to generate the report for any desired duration. The report can be generated either in Excel or PDF format.

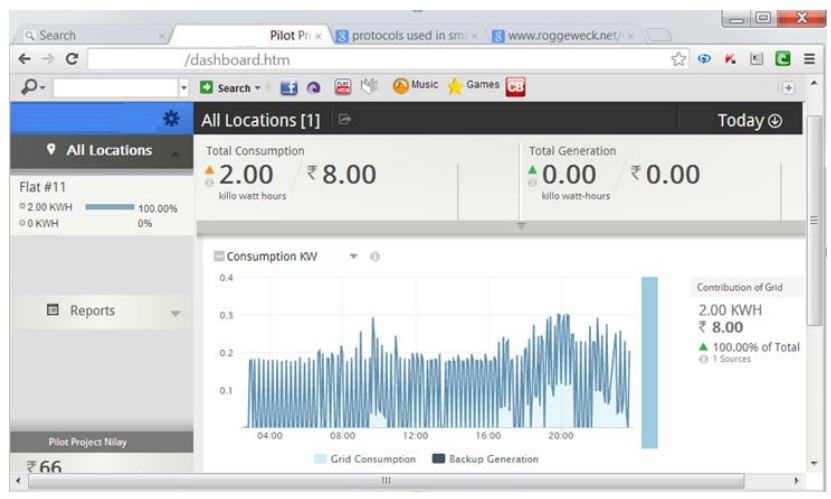

Fig.12 Web page of web portal
Fig. 12 shows the window to generate the report of $\mathrm{kW}$ or $\mathrm{kWh}$ between any desired time duration for flat \#11.

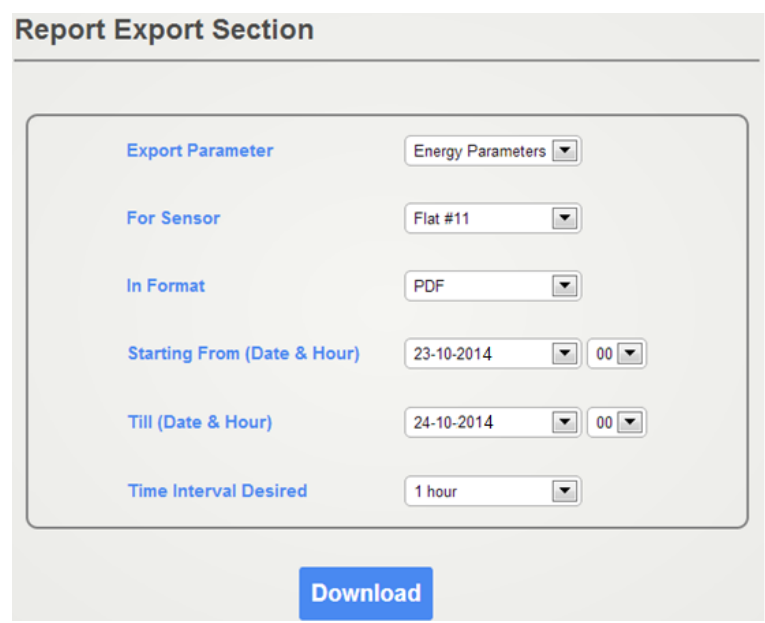

Fig.13 Window to generate report

\begin{tabular}{|c|c|c|c|c|}
\hline \multicolumn{3}{|c|}{ Average Data Report For : Flat \#11 } & \multicolumn{2}{|c|}{ For :23/10/2014 } \\
\hline & CURRENT & KVA & KW & VOLTAGE \\
\hline $23-0 c t 201401: 00: 00$ & 2.79 & 0.67 & 0.64 & 242.99 \\
\hline $23-0$ ct: $201402: 00: 00$ & 2.61 & 0.63 & 0.60 & 243.52 \\
\hline 23-0ct:201403:00:00 & 2.73 & 0.66 & 0.64 & 245.34 \\
\hline $23-0 \mathrm{ct} 201404: 00: 00$ & 2.52 & 0.61 & 0.59 & 246.78 \\
\hline $23-0 \mathrm{ct} \cdot 201405: 00: 00$ & 0.66 & 0.16 & 0.10 & 245.88 \\
\hline $23-0$ ct $201406: 00: 00$ & 0.67 & 0.16 & 0.11 & 24279 \\
\hline 23 -Oct 2014 07:00:00 & 0.59 & 0.14 & 0.08 & 240.84 \\
\hline $23-0 \mathrm{cl} \cdot 201408: 00: 00$ & 0.67 & 0.16 & 0.12 & 240.57 \\
\hline 23 -Oct: $201409: 00: 00$ & 1.07 & 0.25 & 0.21 & 238.51 \\
\hline $23-0 \mathrm{cl} \cdot 201410: 00.00$ & 7.02 & 1.63 & 1.60 & 235.01 \\
\hline 23 -0ct 2014 11:00:00 & 0.65 & 0.15 & 0.11 & 238.26 \\
\hline $23-0 \mathrm{cl} \cdot 201412: 00: 00$ & 0.99 & 0.23 & 0.21 & 238.43 \\
\hline 23 -Oct:201401:00:00 & 1.06 & 0.25 & 0.23 & 241.53 \\
\hline 23 -0ct:201402:00:00 & 1.05 & 0.25 & 0.23 & 239.00 \\
\hline $23-0 \mathrm{ct} 2014$ 03:00:00 & 0.96 & 0.23 & 0.20 & 240.35 \\
\hline $23-0$ ct 2014 04:00:00 & 0.85 & 0.20 & 0.17 & 240.93 \\
\hline 23 -0ct 2014 05:00:00 & 0.97 & 0.23 & 0.21 & 240.83 \\
\hline 23 -Oct:201406:00:00 & 0.90 & 0.21 & 0.18 & 240.71 \\
\hline $23-0 \mathrm{cl} \cdot 201407: 00.00$ & 1.01 & 0.23 & 0.21 & 236.68 \\
\hline $23-0 c t 201408: 00: 00$ & 1.08 & 0.25 & 0.24 & 239.89 \\
\hline $23-0 \mathrm{cl} 201409: 00: 00$ & 0.93 & 0.21 & 0.18 & 235.15 \\
\hline $23-0 \mathrm{cl}-201410: 00: 00$ & 0.75 & 0.17 & 0.14 & 235.57 \\
\hline $23-0 \mathrm{ct} 2014$ 11:00:00 & 0.65 & 0.15 & 0.11 & 233.76 \\
\hline $24-\mathrm{OCl}-2014$ 12:00:00 & 1.26 & 0.30 & 0.27 & 240.97 \\
\hline
\end{tabular}

Fig.14 Generated report in PDF

The generated report is shown in Fig.14. This figure shows the data of various electrical quantities at every 1 hour duration. The present $\mathrm{kW}$ data is compared with contract load of the customer continuously. The red dotted line of Fig. 15 shows the contract load of customer. Its value is $2.44 \mathrm{~kW}$. We can easily find that during which time interval the demand exceeds the contract one. As shown in Fig.15 around 9:30 A.M. customers kW demand exceeds the contract demand (of $2.44 \mathrm{~kW}$ ).

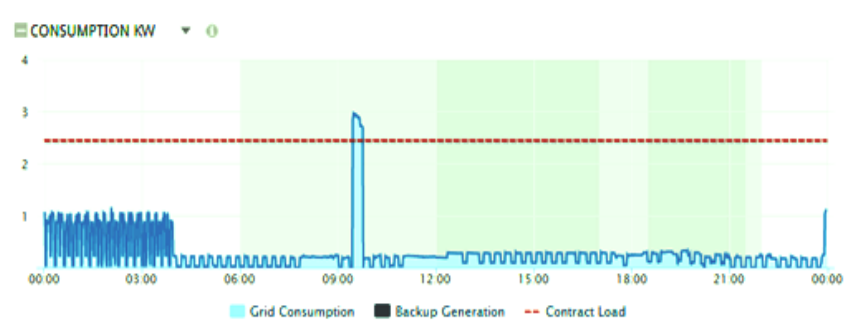

Fig.15 Actual load and contract demand (straight line) of customer 
The data of consumed energy at every span of 15 minute is shown in Fig.16. Customers can get data of spent money during any specified time interval.

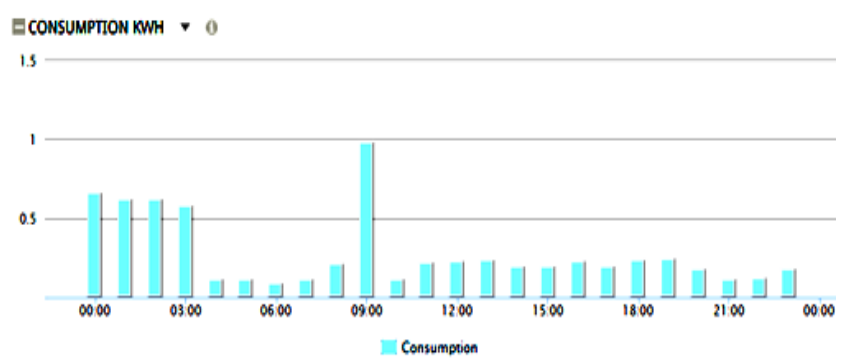

Fig.16 Daily energy consumption (in spell of 15 minutes)

\section{CONCLUSION}

In this paper concept of smart power scheduling of domestic appliances is presented as a part DR strategy. With help of smart energy meter and real time pricing signal customer can dynamically respond to increment in energy charge. By shifting the schedulable load during the lower energy price duration customer can save energy cost.

The architecture and operation of smart energy mete are outlined here. The smart meter sends data of various electrical quantities at every minute to the server. Customer can generate the report of any time duration with help of web portal. If customer's load demand exceeds the value of contract demand, an alert message is sent to the customer through e-mail and SMS. It is shown in the simulation that with help of HEC the total power demand is kept below $P_{\max }, t$. In the simulation it is shown that by shifting the load during the low price duration (off peak period) we can save energy cost by $4.1 \%$. By this manner customers can be encouraged to use the energy during the availability of renewable energy and they can reduce the emission of green house gases also.

In future (after the sanctioning the grant of this project) the smart meters will be installed to all the 11 houses as per the scheme shown in the Fig. 6. This scheme (for distribution network) is very helpful not only to customers but power companies also as it reduces man power, detects power theft very accurately and detects faults very fast in the distribution networks.

\section{ACKNOWLEDGEMENT}

The authors acknowledge gratefully the support provided by the Ecolibrium Energy, Ahmedabad, India.

\section{REFERENCES}

[1] Ye Yan, Yi Quin, Hamid Sharif and David Tipper, "A Survey on Smart Grid Communication Infrastructures: Motivations, Requirements and Challenges" Communications Surveys and Tutorials, IEEE. Issue 99, p.p. 1-16., Feb 2012.

[2] Hengsong wang, Qi Huang, "A Novel Structure For Smart Grid Oriented To Low-Carbon Energy" Innovative Smart Grid Technologies (ISGT) 2011, IEEE PES, p.p. 1-8, 17-19 Jan 2011.

[3] Wang, J.; Biviji, M.; Wang, W.M. " Case Studies Of Smart Grid Demand Response Programs In North America" Innovative Smart Grid Technologies (ISGT) 2011, IEEE PES, pp 1-5, 17-19 Jan 2011.

Copyright to IJIREEICE
4] Koen KOK, Stamatis KARNOUSKOS, Jan RINGELSTEIN, Aris DIMEAS, Anke WEIDLICH, Cor WARMER, Stefan DRENKARD, Nokos HATZIARGYRIOU, Valy LIOLIOU, " Field Testing Smart Houses For A Smart Grid”, $21^{\text {st }}$ International Conference on Electricity Distribution, p.p. 1-4, Frankfurt, 6-9 June 2011.

[5] Abiodun Iwayemi, Peizhong Yi, Xihua Dong, and Chi Zhou, Illinois Institute of Technology "Knowing When to Act:An Optimal Stopping Method for Smart Grid Demand Response", p.p.44-48 IEEE Network. September-October 2011

6] Raja Verma, Patroklos Argyroudis, Donal O'Mahony, "Matching Electricity Supply and Demand using Smart Meters and Home Automation" Conference on Sustainable Alternative Energy (SAE), IEEE PES/IAS, Sep 2009.

[7] Tarek Khalifa, Kshirasagar Naik and Amiya Nayak, "A Survey of Communication Protocols for Automatic Meter Reading Applications" IEEE COMMUNICATIONS SURVEYS \& TUTORIALS, VOL. 13, NO. 2, p.p.168-182, SECOND QUARTER 2011

[8] Abraham. Zhi Zhou, Fei Zhao and Jianhui Wang, “Agent-Based Electricity Market Simulation With Demand Response From Commercial Buildings" IEEE TRANSACTIONS ON SMART GRID, VOL. 2, NO. 4, p.p. 580-588,DECEMBER- 2011

[9] Alec Brooks, Ed Lu, Dan Reicher, Charles Spirakis, and Bill Weihl, "Demand Dispatch- Using Real-Time Control of Demand to Help Balance Generation and Load" IEEE Power An Energy Magazine p.p. 20-29, May-June 2011

[10] Shengnan Shao, Manisa Pipattanasomporn, and Saifur Rahman, "Grid Integration of Electric Vehicles and Demand Response With Customer Choice", IEEE TRANSACTIONS ON SMART GRID, VOL. 3, N0. 1, p. p. 543-550, March 2012

[11] Gang Xiong, Chen Chen, Shalinee Kishore and Aylin Yener, Alec Brooks, Ed Lu, Dan Reicher, Charles Spirakis, and Bill Weihl, "Smart (In-home) Power Scheduling for Demand Response on the Smart Grid" Innovative Smart Grid Technologies (ISGT) 2011, IEEE, p.p. 1-7, Jan 2011. 